\title{
Use of Therapeutics in Pregnancy and Lactation
}

\author{
Sara Eyal ${ }^{1,2}$ (D)
}

Received: 13 March 2018 / Accepted: 15 March 2018 / Published online: 23 March 2018

(C) Springer Science+Business Media, LLC, part of Springer Nature 2018

\begin{abstract}
This theme issue of Pharmaceutical Research is dedicated to drug research and therapy in pregnant and breastfeeding woman. Enthusiasm for studying drug safety and toxicity in these patients (and in their children) has risen over the past decade. Yet, the accumulation of data is slow. A combined effort of industry, regulators, academia and clinicians can promote the treatment of these populations, as discussed in detail in this issue.
\end{abstract}

"The female reproductive system is extremely complicated, because females contain a great many organs, with new ones being discovered every day"

Dave Barry, 1984 (1)

Pregnant and breastfeeding women are orphan populations with regard to drug safety and efficacy, because they have been historically excluded from clinical trials. Less than $3 \%$ of prescription medications approved by the U.S. Food and Drug Administration (FDA) between 2000 and 2010 had enough information to determine their teratogenic risk. The mean time necessary to assign a more precise risk to treatments initially judged to have an "undetermined" risk is 27 years (2). Furthermore, new findings may emerge on drugs that have been on the market for decades with relatively established risk estimation. For instance, valproic acid was first

Guest Editor: Sara Eyal

Sara Eyal

sarae@ekmd.huji.ac.il

Institute of Drug Research, School of Pharmacy, The Hebrew University, Jerusalem, Israel

2 Institute of Drug Research, School of Pharmacy, Faculty of Medicine, The Hebrew University, Ein Kerem, Jerusalem, Israel approved for the treatment of epilepsy in 1967 and its structural teratogenicity has been recognized in the early 1980s. Three decades later, findings from the Neurodevelopmental Effects of Antiepileptic Drugs (NEAD) prospective study indicated that children exposed to this drug in utero had IQ scores 6-10 points lower at ages 3 years (3) and 6 years (4), as compared to children exposed to other antiepileptic drugs. Valproic acid use during pregnancy has also been associated with other worse neurobehavioral outcomes, including increased risk of autism spectrum disorders of the offspring $(5,6)$. These observations raised legal and ethical issues and led to changes in recommendations and guidelines (7-9) and in prescribing patterns of this drug for women of childbearing potential.

Given the consistent lack of safety information, combined with concerns among pregnant women following the thalidomide and other therapeutic disasters, it is not surprising that these patients avoid drugs. A recent study in the U.S. of approximately 1.9 million pregnancies found that the median prevalence ratio of use of 34 drugs was 0.2 comparing pregnant to nonpregnant periods, further increasing the challenges of studying the safety of these medications (10). Likewise, data on safety during lactation are scarce for most approved drugs (11).

The articles in this theme issue of Pharmaceutical Research cover a broad spectrum of topics related to the pharmacokinetics and pharmacodynamics of drugs in pregnancy and lactation. Drug development and pharmacotherapy in pregnant and breastfeeding women are a special challenge not only because of the potential risk to the child, but also because pharmacokinetics and drug effects on the mother may change during pregnancy (and again postpartum, in parallel with initiation of breastfeeding). In this context, Koren and Pariente present a review of pregnancy-induced pharmacokinetic changes and their clinical implications (12). They describe pregnancy-related alterations in drug absorption, distribution and elimination as well as the silent pharmacokinetic 
parameter, drug adherence. Also highlighted is the absence of pregnancy-targeted dose schedules, especially when compared to existing dose modifications, for example in renal failure or in young children.

In addition to maternal pharmacokinetics, an important determinant of fetal exposure is the placenta. The placenta is involved in the pathophysiology of many adverse pregnancy outcomes (13), but potential adverse placental drug effects have been generally overlooked and are only now beginning to be recognized. Our review of placental pharmacokinetics and pharmacodynamics describes the current knowledge on the transfer of small molecules, biologics, and nanoformulations across the placenta and the effects of these therapeutics on the placental barrier itself (14).

The developing brain is protected by additional distributional barriers, namely the blood-brain barrier (BBB) and the blood-cerebrospinal fluid barrier (BCSFB). Ghersi-Egea, Saudrais, and Strazielle review the development of these barriers and describe factors that can affect cerebral drug disposition (15). Also discussed is the higher vulnerability of the developing brain to insults of various types and the potential impact of such injuries on cerebral drug distribution. The authors additionally point to the need for thorough investigation of the developmental pattern of transcytosis mechanisms, which are relevant for newer generation drugs and drug formulations.

Two articles in this issue provide clear examples of the still expanding knowledge on adverse fetal outcomes of drugs that have been in clinical use for many years. The review by Ornoy addresses a gap in literature by describing the available information on treating attention deficit hyperactivity disorder in pregnant and breastfeeding women (16). Equally important, the fields in which knowledge is not available are highlighted. For example, methylphenidate crosses the placenta and achieves significant cerebral concentrations in experimental animal models, but data on the neurodevelopmental effects of methylphenidate in humans are scarce. The other article, by Ziv, Perlman, Masarwa, Ziv and Matok, is a systemic review and meta-analysis of pregnancy outcomes following exposure to quinolone antibiotics (17). Reports on quinolone toxicity to connective tissues in animals, together with the limited information on the safety of quinolones during pregnancy, have led to restricted use of these drugs in young children, neonates, and pregnant women. The meta-analysis presented by Ziv et al. included twelve studies and found that based on the available data, first-trimester exposure to quinolones is not associated with adverse pregnancy outcomes, thus suggesting that restrictions on prescribing quinolones during early pregnancy may be reconsidered. This study demonstrates how the power of meta-analysis can be harnessed to provide better information on drug safety in pregnant women.

Finally, a review by Anderson describes the state-of-the-art of studying drug pharmacokinetics and pharmacodynamics in breastfeeding mothers and their infants. Exposure of the nursing infant to maternal drugs is overall lower as compared to exposure during pregnancy and teratogenicity is not a concern. Safety in lactation can be more directly assessed by sampling of breast milk and, in some cases, infant blood (18). The review elaborates the factors that affect the passage of drugs to breast milk and their pharmacokinetics in the nursing infant, models and designs of lactation studies, and regulatory issues. A special focus is put on modeling of drug passage to breast milk and to the nursing infant, with examples of the utility and limitations of the various modeling approaches.

The growing need for understanding, or even predicting, drug efficacy in pregnancy and lactation led regulatory agencies to change their policies and issue new research initiatives, including establishment of postmarketing pregnancy registries and collaborative research networks (19). Pharmacometric approaches that are especially suitable for the sparse data available from studies in pregnant and breastfeeding women are being increasingly used. In addition, new drug and biological product labeling standards, the Pregnancy and Lactation Labeling Rule (PLLR), became effective on 30 June 2015 (20). The new system is a more descriptive report that summarizes the data about the risks and any other relevant information on drug use in pregnancy and lactation. Yet, to enhance the transparency and impact of this system, it has to be supported by data provided by industry and clinicians. To this point, in the era of personalized and stratified medicine, pregnant and breastfeeding women (and their children) should be recognized as special populations that can be included in research in order to address their needs. As with other special populations, the data gained through such studies can provide new opportunities for the development of drugs and drug delivery systems for these patients. In the meantime, pharmacometric approaches and meta-analyses can support decision-making by healthcare professionals.

The author has no commercial or financial relationships that could be construed as a potential conflict of interest.

\section{REFERENCES}

1. Barry D. Babies and other hazards of sex: how to make a tiny person in only 9 months, with tools you probably have around the home. New York: St. Martin's Press; 1984.

2. Adam MP, Polifka JE, Friedman JM. Evolving knowledge of the teratogenicity of medications in human pregnancy. Am J Med Genet C Semin Med Genet. 2011;157c:175-82.

3. Meador KJ, Baker GA, Browning N, Clayton-Smith J, CombsCantrell DT, Cohen M, Kalayjian LA, Kanner A, Liporace JD, Pennell PB, Privitera M, Loring DW, NEAD Study Group. Cognitive function at 3 years of age after fetal exposure to antiepileptic drugs. N Engl J Med 2009;360:1597-1605.

4. Meador KJ, Baker GA, Browning N, Cohen MJ, Bromley RL, Clayton-Smith J, Kalayjian LA, Kanner A, Liporace JD, Pennell PB, Privitera M, Loring DW, NEAD Study Group. Fetal 
antiepileptic drug exposure and cognitive outcomes at age 6 years (NEAD study): a prospective observational study. Lancet Neurol 2013;12:244-252.

5. Christensen J, Grønborg TK, Sørensen MJ, Schendel D, Parner ET, Pedersen LH, et al. Prenatal valproate exposure and risk of autism spectrum disorders and childhood autism. JAMA. 2013;309: 1696-703.

6. Wood AG, Nadebaum C, Anderson V, Reutens D, Barton S, O'Brien TJ, et al. Prospective assessment of autism traits in children exposed to antiepileptic drugs during pregnancy. Epilepsia. 2015;56:1047-55.

7. European Medicines Agency. Assessment Report. Procedure Under Article 31 of Directive 2001/83/EC Resulting from Pharmacovigilance Data. 2014. http://www.ema.europa.eu/ docs/en_GB/document_library/Referrals_document/Valproate and_related_substances_31/Recommendation_provided_by_ Pharmacovigilance_Risk_Assessment_Committee/ WC500177352.pdf. Accessed March 102018.

8. U.S. Food \& Drug Administration. FDA Drug Safety Communication: Valproate Anti-seizure Products Contraindicated for Migraine Prevention in Pregnant Women due to Decreased IQ Scores in Exposed Children. https://www. fda.gov/drugs/drugsafety/ucm350684.htm. Updated February 26 2016. Accessed March 102018.

9. Tomson T, Marson A, Boon P, Canevini MP, Covanis A, Gaily E, et al. Valproate in the treatment of epilepsy in girls and women of childbearing potential. Epilepsia. 2015;56:1006-19.

10. Illoh OA, Toh S, Andrade SE, Hampp C, Sahin L, Gelperin K, et al. Utilization of drugs with pregnancy exposure registries during pregnancy. Pharmacoepidemiol Drug Saf. 2018 Epub Mar 8.
11. Anderson PO, Manoguerra AS, Valdes V. A review of adverse reactions in infants from medications in breastmilk. Clin Pediatr (Phila). 2016 Mar;55:236-44.

12. Koren G, Pariente G. Pregnancy- associated changes in pharmacokinetics and their clinical implications. Pharm Res. 2018;35:61.

13. Ilekis JV, Tsilou E, Fisher S, Abrahams VM, Soares MJ, Cross JC, et al. Placental origins of adverse pregnancy outcomes: potential molecular targets: an executive workshop summary of the Eunice Kennedy Shriver National Institute of Child Health and Human Development. Am J Obstet Gynecol. 2016;215:S1-S46.

14. Tetro N, Moushaev S, Rubinchik-Stern M, Eyal S. The placental barrier: the gate and the fate in drug distribution. Pharm Res. 2018;35:71.

15. Ghersi-Egea JF, Saudrais E, Strazielle N. Barriers to drug distribution into the perinatal and postnatal brain. Pharm Res. 2018;35:84.

16. Ornoy A. Pharmacological treatment of attention deficit hyperactivity disorder during pregnancy and lactation. Pharm Res. 2018;35:46.

17. Ziv A, Perlman A, Masarwa R, Ziv D, Matok I. Pregnancy outcomes following exposure to quinolone antibiotics - a systemic review and meta-analysis. Pharm Res. 2018. In Press.

18. Anderson PO. Drugs in lactation. Pharm Res. 2018;35:45.

19. Illamola SM, Bucci-Rechtweg C, Costantine MM, Tsilou E, Sherwin CM, Zajicek A. Inclusion of pregnant and breastfeeding women in research - efforts and initiatives. Br J Clin Pharmacol. 2018;84:215-22.

20. U.S. Food \& Drug Administration. Pregnancy and Lactation Labeling (Drugs) Final Rule. https://www.fda.gov/Drugs/ DevelopmentApprovalProcess/DevelopmentResources/Labeling/ ucm093307.htm. Updated March 12 2014. Accessed March 102018. 